\title{
Correspondence
}

\section{Move on to a carbon currency standard}

Alongside Robert Costanza and colleagues' plea to abandon gross domestic product as a measure of national success (see Nature 505, 283-285; 2014), we believe that there is an urgent need to change the way currencies are valued by using a new 'carbon standard' that links economy to ecology.

This would work in a similar way to the old gold-exchange standard, except that a country's currency value would instead be determined by its saved and standing stocks of fossil and non-fossil carbon. Governments would need to decide whether to risk devaluing their currency by depleting carbon stocks - while still honouring a commitment to keep fossil-carbon stocks at $80 \%$ as a safeguard against extreme climate change.

After the Second World War, huge investments radically altered the economies of the United States, the Soviet Union and the United Kingdom. In the face of climate change, it is now the global energy system that needs reinvention.

John R. Porter University of Copenhagen, Denmark. jrp@plen.ku.dk

Steve Wratten Lincoln University, New Zealand.

\section{Apply market forces to peer review}

Dan Graur suggests that journals should devise a system to tie in the number of papers they publish from senior researchers with the reviewing record of those authors (Nature 505, 483; 2014). This is comparable to linking the amount of milk you drink to the number of cows you milked.

In a market economy, the monetary value of services is determined by the laws of supply and demand. When it comes to the highly skilled service of peer reviewing, the supply is sufficiently high to keep the monetary value at zero.

If, at a constant level of demand, the supply is reduced, then this price would go up. With an increased price, people could become professional reviewers to supplement their salary. Instead of making it harder for scientists to decline their reviewing requests, journals should be allowing market forces to exert their natural effect.

Sascha Ott, Daniel Hebenstreit University of Warwick, UK. s.ott@warwick.ac.uk

\section{Drug-resistant TB can be contained}

The spread of multi-drugresistant tuberculosis (MDR-TB) in Russia is by no means unstoppable (Nature http:// doi.org/rf3; 2014). MDR-TB epidemics have been prevented and/or reversed in Latvia, Estonia, Hong Kong and the United States, and even in the hard-hit Russian provinces of Orël and Tomsk, by using evidence-based policies and patient-centred care.

Containing the airborne spread of MDR-TB requires transmission to be interrupted, treatment of active disease
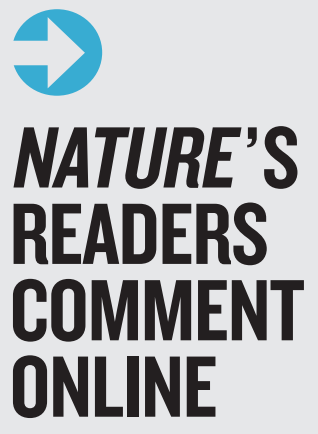

A selection of views on the topic of senior scientists turning down review requests (D. Graur Nature 505, 483; 2014).

with the right antibiotics for the correct amount of time, treatment of latent infection, and locating cases and their contacts.

As a result of political determination and a series of intervention programmes, the Tomsk Oblast TB services, in conjunction with Partners In Health, based in Boston, Massachusetts, reduced MDR-TB prevalence from an estimated 823 cases in 2002 to 328 in 2012. These reductions were the result of structural changes (better facilities, treatment sites and community-based care), clinical improvements (individualized drug regimens and aggressive management of adverse events) and social interventions (treatment incentives and assistance with food and transportation).

The complexity and expense of MDR-TB treatment take a huge toll on patients and carers. We urgently need better diagnostics, shorter and less-toxic treatments, and more research and resources. Even with existing resources, much more is possible.

Erica Lessem Treatment Action Group, New York, USA.

erica.lessem@

treatmentactiongroup.org

Paul Flicek says:

Graur makes the anecdotal observation that those scientists who publish most often are more likely to turn down requests to review papers. But manuscripts are only a part of a senior scientist's peer-reviewing activities: these include peer review for individuals and institutions, and of many more grant applications than they themselves submit.

\section{S. Sudha Tushara and}

S. Sudarsan say:

A reviewing 'impact factor' awarded to reviewers per paper would entice reviewers, and help editorial boards and funding agencies.
Salmaan Keshavjee Harvard Medical School, Boston, Massachusetts, USA.

\section{Sci-fi should not discredit vaccines}

Ordinarily, I would not consider a deviation from absolute scientific truth to be a problem in science fiction. But I am disturbed by the dangerous and incorrect implications in A. G. Carpenter's Futures story that vaccines weaken the human immune system, and that their effects are on a par with poisoning by lead or tobacco (Nature 506, 126; 2014).

Vaccines are safe, effective and rigorously tested (see, for example, Nature Immunol. 9, 1317; 2008). Ungrounded fears already prompt parents unnecessarily to opt out of vaccination programmes for their children, leading to entirely avoidable illnesses and diminishing herd immunity.

In my view, it is irresponsible to promote the idea that vaccines are bad for health - even fictitiously.

Rachel Reddick Stanford University, California, USA. rmredd@stanford.edu

\section{Bob O'Hara says:}

Perhaps scientists who publish more are asked to review more, and thus even if they review as many manuscripts as everyone else, they will still appear to be less cooperative because they decline more manuscripts.

\section{S. A. Luis, M. Madadin and} R. G. Menezes say: Nominal financial incentives would help too, as would mandating involvement with peer review as a prerequisite for academic promotion.

Samad E. J. Golzari says: The quality of a mandatory peer review might not be the same as a review undertaken voluntarily. 